\title{
Renin-Angiotensin and Kallikrein-Kinin Systems in Diabetic Retinopathy
}

Rajko Igić1,2,3

\section{ABSTRACT}

This brief review describes how two complex systems, the renin-angiotensin system (RAS) and the kallikrein-kinin system (KKS), affect the retina. It emphasises the important physiological actions of components of these systems, the protective effectiveness of angiotensin I converting enzyme (ACE) inhibitors and angiotensin receptor blockers (ARB) in diabetic retinopathy and suggests as well the therapeutic possibilities for treatment of diabetic retinopathy by selective activation of bradykinin receptors (B1 and $\mathrm{B} 2$ ).

Key words: RAS, KKS, ACE, angiotensin II, kinins, ACE inhibitors.
(1) Department of Anaesthesiology and Pain Management, John Stroger Hospital of Cook County, Chicago, Illinois 60612, USA.

(2) Faculty of Medicine, University of Banja Luka, 78000 Banja Luka, the Republic of Srpska, Bosnia and Herzegovina.

(3) Medical Centre, 25000 Sombor, Serbia

Correspondence:

RAJKO IGIĆ

E: r.igic@excite.com

ARTICLE INFO

Submitted: 11 September 2019 Accepted: 17 September 2019

\section{INTRODUCTION}

The aim of this article is to assess a role of the renin-angiotensin system (RAS) and the kallikrein-kinin system (KKS) in diabetic retinal microvascular damage. Diabetes is a major risk for loss of vision due to retinopathy and its major complication, macular oedema. The chronic hyperglycaemia of diabetes mellitus disrupts carbohydrate, fat, and protein metabolism by deficiencies of insulin secretion, insulin action, or both. In type 1 diabetes the pancreas produces very little or no insulin. Specific autoimmune markers indicate that an autoimmune process damages or destroys pancreatic beta cells in the majority of patients (nearly 90\%) with type 1 diabetes.

Type 2 diabetes, the more common form of diabetes, affects both insulin action and insulin secretion. This form of the disease frequently occurs in elderly patients, and it is the most common cause of microvascular damage that may present as coronary artery disease, nephropathy, peripheral neuropathy, and retinopathy.

\section{Renin-angiotensin and kallikrein-kinin systems}

Renin-angiotensin and kallikrein-kinin systems (Figure 1) are proteolytic cascades that operate at both systemic and local (tissue) levels., ${ }^{1,2}$ Studies of their role in the eye have focused on distribution and participation in diseases, such as glaucoma, diabetic retinopathy, age-related macular degeneration and uveitis. This short presentation explores the therapeutic potential of some pharmacological agents that could affect diabetic retinopathy (DR).

The RAS components consists of twenty peptidases, nearly twenty angiotensin peptides, and six receptors. ${ }^{3}$ According to the classic view, the RAS is an endocrine system. Renin, which is produced in the kidney, acts on angiotensinogen in the circulation to form a biologically inactive decapeptide, angiotensin I, which is then converted by angiotensin converting enzyme (ACE) to a potent vasoconstrictor peptide, angiotensin II. Angiotensin II stimulates aldosterone synthesis and regulates blood pressure, fluid volume, electrolytic balance, and inflammation. 


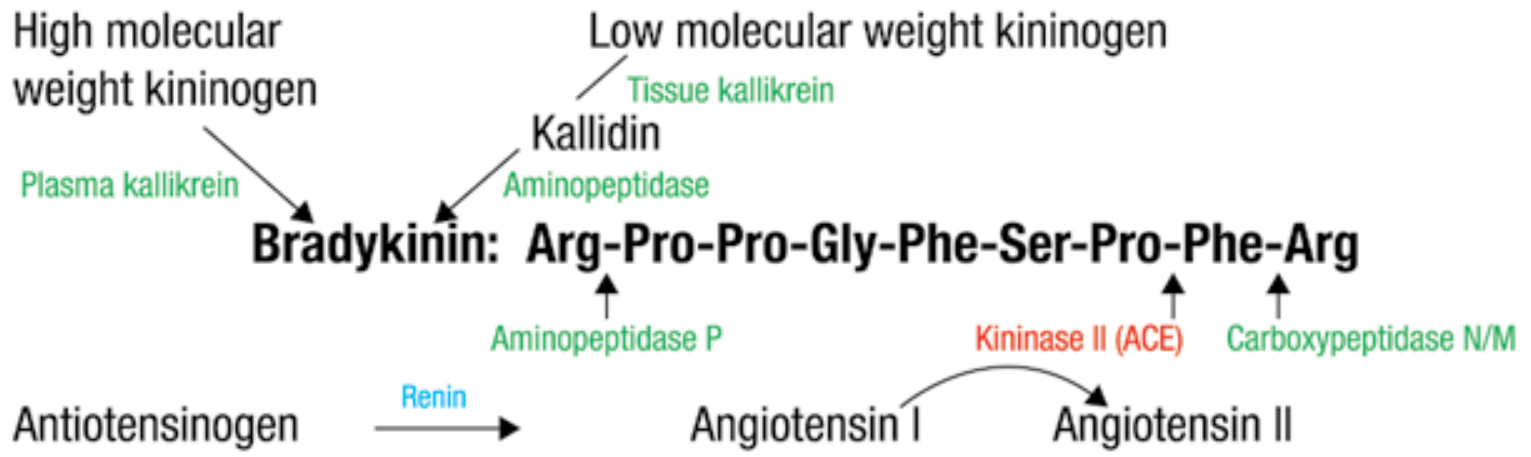

Figure 1: Peptidases and peptides of the KKS and a portion of the RAS. The enzymes in the KKS are shown in green, while renin is shown in blue; ACE, which acts in both systems, in shown in red.

This octapeptide acts through two types of receptors, AT1 and AT2. Originally it was assumed that the RAS acts as an endocrine system, but this view changed when it was shown that the RAS operates at both systemic and tissue levels. ${ }^{4}$

ACE was discovered in the blood, but it is also found within endothelial and epithelial cells of the lungs, kidneys, the male genital tract and other tissues, as well as within body fluids, and retinal extracts from man, guinea pig, hog, and rabbit eyes. ${ }^{5}$ ACE converts angiotensin I (AspArg-Val-Tyr-Ile-His-Pro-Phe-His-Leu) to angiotensin II by cleaving a dipeptide, His-Leu from the C-teminal end of angiotensin I. The proline (Pro7) location in the penultimate position of angiotensin $\mathrm{II}^{6}$ prevents further cleavage by ACE. However, the enzyme also cleaves C-terminal dipeptides from various other peptide substrates, including bradykinin, kallidin, enkephalin, substance $\mathrm{P}$ and neurotensin. Under normal conditions, in comparison to other organs, lung tissue has the highest ACE activity and the kidney the lowest. However, in individuals with genetically high ACE activities, especially diabetic subjects, this enzyme causes higher inactivation of kinins (bradykinin and kallidin) than angiotensin II production. ${ }^{7}$

The components of KKS are present only in mammals. ${ }^{8}$ Kallikreins release kinins from two substrates: high molecular weight kininogen, or Fitzgerald factor (factor XII, $100 \mathrm{kDa}$ ), and a low molecular weight (50-68 kDa) kininogen. Both are synthesised in the liver and are abundant in plasma. Plasma kallikrein (Fletcher factor) releases bradykinin (Arg-Pro-Pro-Gly-Phe-SerPro-Phe-Arg), while tissue kallikrein releases kallidin. ${ }^{9}$ Both kinins act upon two types of receptors, B1 and B2. Under the most conditions, kinins act through $\mathrm{B} 2$ receptors, increasing vasodilatation, vascular permeability and by in- creasing intracellular calcium in smooth muscle and endothelium via increased nitric oxide and prostacyclin release from endothelial cells. DesArg9 bradykinin and des-Arg10-kallidin activate the B1 receptor, which is rapidly expressed in inflammation or tissue injury. Kinins have a short half-life, less than 15 seconds. They are inactivated by two types of kininases: kininase II or ACE and carboxypeptidases $\mathrm{N}$ and $\mathrm{M}$ and also by aminopeptidase..$^{10,11}$

Interactions between the RAS and KKS occur at three enzyme levels: ACE, kallikrein, and prolylcarboxypeptidase (PRCP). Additional interactions between the two systems occur at B2 receptors, and also at angiotensin $\mathrm{AT}_{1}$ and $\mathrm{AT} 2$ receptors. These interactions indicate a degree of co-dependence, but the KKS does not always counterbalance the RAS. Sometimes both systems act in the same direction, eg during tissue injury. ${ }^{12}$

ACE inhibitors block angiotensin II release and catabolism of kinins (bradykinin and kallidin), but they also amplify the role of other enzymes that hydrolyse angiotensin I and kinins by increasing release of other biologically active products, such as angiotensin 1-7 and angiotensin 1-9. ${ }^{13}$ These peptides oppose angiotensin II activity and potentiate kinin action in various tissues, especially in the heart. ${ }^{14}$

\section{Renin-angiotensin and kallikrein-kinin systems in the eye \\ Van Haeringen in the British Journal of Oph- thalmology (1996) noted that "Opthalmic liter- ature concerning the RAS started in 1977 with a study by Igic and co-workers on the detection of ACE activity in homogenates of the retina." 15 Since then we have continued to study the role of the RAS in the eye.}


The blood-ocular barrier prevents the passage of peptides and larger molecules, such as angiotensin I, angiotensin II, kinins, renin, angiotensinogen, kallikreins, and ACE. However, ocular tissue of various species, including humans, contains the components of both the RAS and KKS. ${ }^{5,6-18}$ In addition, concentrations of prorenin, angiotensin I, ACE, and angiotensin II are higher in the retina, choroid and anterior uveal tract than in plasma. The local production of these RAS components in the eye is similar to tissue generation of these peptides in other organs, including the kidney, brain, adrenals, and reproductive tract. Distribution of ACE within human vascular tissues varies. Most of the vascular ACE is generally found in small muscular arteries and arterioles, but capillaries, large arteries, veins and venules have little of this enzyme. Pulmonary, renal and retinal capillaries, with high activities of ACE, are an exception to this distributive pattern. ${ }^{19,20}$

The components of the KKS (kallikrein, B1 and B2 receptor proteins and kinin-inactivating enzymes, are found in various parts of the eye..$^{21,22}$ Because the concentration of kallikrein is lower in plasma than in homogenates of retinal tissue, it is unlikely that the retinal enzyme is a contaminate from blood. Endothelial ACE increases in diabetes resulting in locally increased generation of angiotensin II and simultaneous decreases in kinin activities. Individuals with genetically increased ACE activities have a greater risk for cardiovascular damage, including retinopathy, neuropathy and nephropathy.

\section{Diabetic retinopathy}

Diabetic retinopathy (DR) is a frequent cause of blindness in middle-aged and elderly people. Risk factors include age (primarily 50-70 years), duration and inadequate control of diabetes, hypertension, and hyperlipidemia. In addition to DR, further diabetic eye complications include glaucoma, macular oedema and cataracts. DR may affect the peripheral retina, the macula, or both. ${ }^{23}$ In DR major retinal damage includes varying degrees of micro-aneurisms, exudates, hemorrhages, new vessel formation, and retinal thickening. These diabetic complications are evidence of microvascular disease, but retinal neurodegeneration is also involved.

There are two types of DR - proliferative and non-proliferative. Vascular endothelial growth factor (VEGF) stimulates neovascularisation in proliferative diabetic retinopathy. It was recently shown that the retinal and vitreous RAS regulates VEGF production. ${ }^{24}$ Increased levels of VEGF are found in the vitreous humor and in vascular tissue in the eyes of individuals with proliferative DR. This pro-angiogenic cytokine factor acts at two types of tyrosine kinase receptors involved in the regulation of angiogenesis.

Proliferative DR includes changes in retinal vessel diameters and an increase in vessel permeability. This results in leakage, although the blood retinal barrier persists in both types of DR. The proliferative type exhibits retinal neovascularization extending into the vitreous body. ${ }^{25}$ This abnormality may obstruct the passage of light to the retina, cause haemorrhage, fibrous tissue formation, and produce vitreoretinal traction and retinal detachment. In juvenile diabetics (type 1 diabetes) DR is the major cause of blindness.

Treatment for the proliferative type DR or macular edema includes laser photocoagulation, vitrectomy, or injection of VEGF inhibitors (bevacizumab, ranibizumab, pegaptanib, aflibercept) into the vitreous. The optimal dose and dosing sequence for VEGF inhibitors remain unclear, but higher doses appear to be most effective in inducing regression of neovascularisation. Side effects of laser photocoagulations and injections of the VEGF inhibitors are the reason why other therapeutic options are preferred. Although Anti-VEGF agents are effective in many DR patients, they do not influence the pathogenesis of the retinopathy and the necessity for repeated intravitreal injections over many years poses a permanent risk of adverse effects.

Several innovative therapeutic strategies have sought to improve the treatment of DR and other ocular diseases (eg glaucoma and age-related macular degeneration). Among new lines of investigation, vasoactive peptides (angiotensin II and kinins) were considered as candidates in the pathogenesis of eye diseases. However, E G Erdö ${ }^{26}$ showed that the rapid enzymatic inactivation of these peptides precludes their use as therapeutic agents. If these transient peptides locally influence any specific pathological conditions, only agents that block their effect or inhibit their enzymatic degradation would be useful for therapeutic purposes. This important concept eventually led to the discovery of ACE inhibitors. 
Tissue renin-angiotensin and kallikrein-kinin systems in diabetic retinopathy

The RAS and KKS operate in pulmonary, systemic, and local circulations, including various ocular tissues. The peptides produced by the two systems in the retina (angiotensin II and kallidin) contribute to the regulation of neurovascular retinal function. They influence inflammatory and angiogenic signalling molecules, such as VEGF and chemokines that may participate in both physiological and pathological conditions. Since both the RAS and KKS act to maintain homeostatic regulation and meet the metabolic needs of the retinal tissue, any dysfunction within these systems may damage this highly sensitive tissue.

In addition to retinal tissue, components of the RAS are found in the vitreous humour where they can influence neovascularisation by stimulating VEGF production in proliferative DR. This poses the possibility for early therapeutic interventions, such as the reduction of VEGF and other pro-inflammatory and angiogenic cytokines. Development of a single-strand inhibitory RNA that targets a (pro)renin receptor [(P) $\mathrm{RR}$ ] will be clinically tested in patients with DR and several other eye diseases. ${ }^{24}$ Effectiveness of this ribonucleic acid interference molecule should be also tested in ocular inflammation and angiogenesis.

Endothelial ACE activity often increases in diabetic patients, and this may accelerate the development of nephropathy, neuropathy, and retinopathy. ${ }^{7}$ Genetic variation of ACE activity due to insertion/deletion polymorphism also causes variability in plasma and tissue ACE activities, which may slightly increase the risk of tissue damages in non-diabetic subjects, but in diabetic patients the risk is much higher. Increased production of active ACE results in faster kinin inactivation than conversion of angiotensin I to angiotensin II, accelerating tissue damages.

For these reasons, ACE and ARBs were explored in clinical studies for potential beneficial effects on diabetic retinopathy. ${ }^{27}$ In 21 randomized clinical trials with a total of 13,823 participants, RAS inhibitors reduced risk of progression and increased possibility of regression of diabetic retinopathy. ACE inhibitors proved to have the highest potential for regression of diabetic retinopathy, followed by ARBs, placebo, and calci- um channel blockers. The conclusion was that ACE inhibitors are preferable to ARBs for treating diabetic retinopathy.

Kinins increase vasodilation, vascular permeability, and sweating. An increase in kinin activity by ACE inhibitors would seem beneficial in cardiovascular diseases; the vasodilation caused by these agents may be important for end-organ protection. Locally produced kinins in the eye might help to prevent diabetic retinopathy as well. Because kallikrein activation by gene therapy is unlikely to be easy developed for clinical use, ${ }^{7}$ activation of $\mathrm{B} 1$ or $\mathrm{B} 2$ receptors might be a better pharmacological target. Pseudo-peptide analogues of kinins, resistant to the actions of peptidases, could reduce end/organ damage by activation of those receptors. ${ }^{28,29}$ If receptor activation of $\mathrm{B} 2$ causes side effects, such as angioedema, hypotension or pain, B1 receptor activation may prove to be safer. Initial studies with synthetic pseudo-peptide analogues of kinins in diabetic rats show that prolonged (up to two weeks) treatment by B1 receptor activators produces safe and effective microvascular protection. ${ }^{30,31}$ Although these peptide analogues can be given only intravenously or by osmotic mini pumps, further experiments should examine both $\mathrm{B} 1$ and $\mathrm{B} 2$ receptor activators in animal models of diabetic retinopathy. Such studies may help us to open the road towards discovery an orally effective bradykinin receptor agonist - perhaps the best solution for prevention and treatment of diabetic end-organ damage.

\section{NOTE}

I devote this article to Ervin G Erdös (96), my teacher at postdoctoral training in biochemical pharmacology (Oklahoma City, 1970-1972) and a good friend. We collaborated in research for several decades ${ }^{2}$. He visited the former Yugoslavia several times where he presented seminars (Sarajevo, Tuzla, Sombor and Belgrade) and stimulated local scientists to study metabolism and activity of vasoactive peptides of diabetic end-organ damage.

\section{DISCLOSURE}

The author declared no competing interests. 


\section{REFERENCES}

1. Igić R. Four decades of ocular renin-angiotensin and kallikrein-kinin systems (1977-2017). Exp Eye Res 2018;166:74-83.

2. Igić R. An exploration of bioactive peptides: my collaboration with Ervin G. Erdös. J Biol Chem 2018;293:7907-15.

3. Ferrao FM, Lara LS, Lowe J. Renin-angiotensin system in the kidney: what is new? World J Nephrol 2014;36476.

4. Škrbić R, Igić R. Seven decades of angiotensin (19392009). Peptides 2009;30;1945-50.

5. Igić R, Kojović V. Angiotensin I converting enzyme (kininase II) in ocular tissues. Exp Eye Res 1980;30:299303.

6. Igić R, Behnia R. Properties and distribution of angiotensin I converting enzyme. Curr Pharm Des 2003;9:697-706.

7. Alhenc-Gelas F, Bouby N, Girolami JP. Kallikrein/K1, kinins, and ACE/kininase II in homeostasis and in disease insight from human and experimental genetic studies, therapeutic implication. Front Med (Lausanne) 2019;6:136. doi: 10.3389/fmed.2019.00136.

8. Seki T, Miwa I, Nakajima T, Erdös EG. Plasma kallikrein-kinin system in nonmammalian blood: evolutionary aspects. Am J Physiol 1973;224:1425-30.

9. Pathak M, Wong SS, Dreveny I, Emsley J. Structure of plasma and tissue kallikreins. Thromb Haemost. 2013;110:423-33. doi: 10.1160/TH12-11-0840.

10. Johnson AR, Skidgel RA, Gafford JT, Erdös EG. Enzymes in placental microvilli: angiotensin I converting enzyme, angiotensinase A, carboxypeptidase, and neutral endopeptidase ("enkephalinase"). Peptides 1984;5:789-96.

11. Zhang X, Tan F, Brovkovych V, Zhang Y, Lowry JL, Skidgel RA. Carboxypeptidase M augments kinin B1 receptor signaling by conformational crosstalk and enhances endothelial nitric oxide output. Biol Chem 213;394:335-45. http://dx.doi.org/10.1515/hsz-20120290.

12. Su JB. Different cross-talk sites between the renin angiotensin and the kallikrein-kinin systems. J Renin Angiotensin Aldosterone Syst 2014;15:319-28.

13. Jackman HL, Massad MG, Sekosan M, Tan F, Brovkovych V, Marcic BM, et al. Angiotensin 1-9 and 1-7 release in human heart: role of cathepsin A. Hypertension 2002;39:976-81.

14. Ferrario CM, Cheng CP, Varagić J. Angiotensin-(1-7) and the heart. In: Santos RAS, editor. Angiotensin-(1-7). New York: Springer, 2019, pp.83-104.

15. Van Haeringen NJ. The renin-angiotensin system in the human eye. Br J Ophthalmol 1996;80:99-100.

16. Igić R, Robinson CJG, Erdös EG. Angiotensin I converting enzyme in the choroid plexus and in the retina. Sixth International Congress of Pharmacology. Helsinki: Book of abstracts, abstract 408, 1975.
17. Danser AH, Derkx FH, Admiraal PJ, Deinum J, de Jong PT, Schalekamp MA. Angiotensin levels in the eye. Invest Ophthalmol Vis Sci 1994;35:1008-18.

18. Choudhary R, Singh M, Kapoor MS, Singh A, Bodakhe $\mathrm{SH}$. Therapeutic targets of renin-angiotensin system in ocular disorders. J Curr Ophtalmol 2016;29:7e16. http://dx.doi.org/10.1016/j.joco.2016.09.009.

19. Metzger R, Franke FE, Bohle RM, Alhenc-Gelas F, Danilov SM. Heterogeneous distribution of angiotensin I-converting enzyme (CD143) in the human and rat vascular systems: vessel, organ and species specificity. Microvasc Res 2011;81:206-15. doi: 10.1016/j. mvr.2010.12.003.

20. Ward PE, Stewart TA, Hammon KJ, Reynolds RC, Igić R. Angiotensin I converting enzyme (kininase II) in isolated retinal microvessels. Life Sci 1979;24:1419-24.

21. Bhat $M$, Pouliot $M$, Couture $R$, Vaucher E. The kallikrein-kinin system in diabetic retinopathy. Prog Drug Res 2014;69:111-43.

22. Igić R. Kallikrein and kininases in ocular tissues. Exp Eye Res 1985;41:117-20.

23. Antonetti DA, Klein R, Gardner TW. Diabetic retinopathy. N Engl J Med 2012;366:1227-39.

24. Kanda A, Ishida S. (Pro)renin receptor: Involvement in diabetic retinopathy and development of molecular targeted therapy. J Diabetes Investig 2019;10:6-17.

25. Díaz-Coránguez M, Ramos C, Antonetti DA. The inner blood-retinal barrier: Cellular basis and development. Vision Res 2017;139:123-37. doi: 10.1016/j.visres.2017.05.009.

26. Erdös EG. In: Garattini S, Shore PA, editors. Advances in pharmacology. Vol. 4, New York: Academic Press, 1966, pp. 1-90.

27. Wang B, Wang F, Zhang Y, Zhao SH, Zhao WJ, Yan SL, et al. Effects of RAS inhibitors on diabetic retinopathy: a systematic review and meta-analysis. Lancet Diabetes Endocrinol 2015;3:263-74. doi: 10.1016/S22138587(14)70256-6.

28. Belanger S, Bovenzi V, Cote J, Neugebauer W, Amblard M, Martinez J, et al. Structure-activity relationships of novel peptide agonists of the human bradykinin B2 receptor. Peptides 2009;30:777-87.

29. Cote J, Savard M, Bovenzi V, Belanger S, Morin J, Neugebauer W, et al. Novel kinin B1 receptor agonists with improved pharmacological profiles. Peptides 2009;30:788-95.

30. Desposito D, Waecked L, Potier l, Richer C, Roussel R, Rouby N, et al. Kallikrein (K1)-kinin-kininase (ACE) and end-organ damage in ischemia and diabetes: therapeutic implications. Biol Chem 2016;397:1217-22.

31. Igić R. Renin-angiotensin and kallikrein-kinin systems in diabetic renal damage. Vojnosanitet Pregl 2019;76(9). https://doi.org/10.2298/VSP190820079I. 